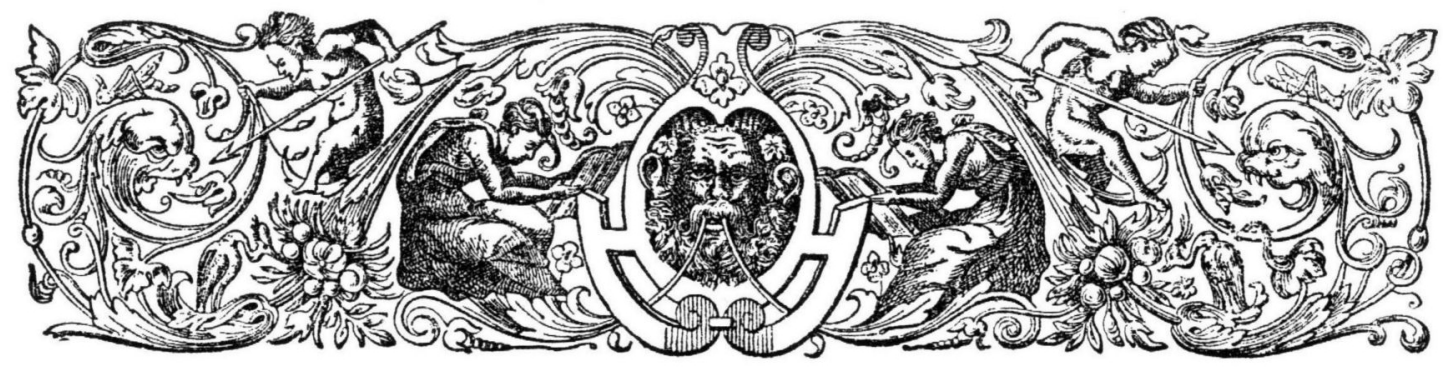

\title{
ITALIAANSCHE SCHILDERIJEN IN I672 DOOR HAAGSCHE EN DELFTSCHE SCHILDERS BEOORDEELD \\ DOOR
}

\author{
A. BREDIUS.
}

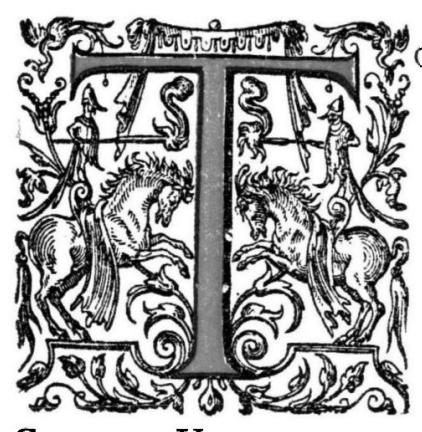

OEN ik in 1886 in Oud-Holland twee stukken plaatste met bijna gelijkluidenden titel, als hierboven staat, dacht ik niet, dat ik bijna dertig jaren later eenige documenten zou vinden, belangrijk genoeg om hier af te drukken, die de toen behandelde aangelegenheid nog nader toelichten.

In 't kort zij hier nog even vermeld, wat die aanGERARD UYLENURG dertien Italiaansche Schilderijen, toegeschreven aan de beroemdste meesters, door bemiddeling van Generaal-Majoor Vrijheer vaN SPAEN aan den Keurvorst van Brandenburg verkocht, het schijnt voor $f 30,000$.- Des Keurvorsten hofschilder, HENDRICK DE Fromantiou, in 167 I met een dochter van PH. Wouwermans getrouwd, verklaarde ze allen, op één na - van RIBERA - voor slechte copyen en vodden. De stukken gingen naar Amsterdam terug, waar beurtelings groepen schilders voor UYLENBURGH verklaarden, dat die stukken niet slecht waren, in elk geval waardig in een kabinet van Italiaansche kunst te hangen en weêr andere schilders voor FROMANTIOU attesteerden dat het waardelooze prullen mochten heeten.

Wat ik toen niet wist, is, dat de 12 schilderijen ook naar den Haag werden gebracht, waar Haagsche en Delftsche schilders er hun meening over lieten boekstaven door den Notaris P. VAN Swieten. Daar Fromantiou hier de 
requirant is, zijn die verklaringen hoogst ongunstig. In den Haag zijn het Deken en Hooftmannen der schildersconfrerie; uit Delft komen twee schilders, beiden "uytmuntende kunstschilders" genoemd. De eene - de Delftsche VERMEER, de andere...... de ons totaal onbekende JOHANNES JORDAEN, niet te verwisselen met den Antwerpschen HaNs JoRDaEns, door zijne doortochten van de Roode Zee bekend.

Dit is eigenlijk het merkwaardigste van deze acten: het in één adem noemen dier twee schilders, waarvan de eene thans tot de meest gevierde, hoogst betaalde behoort, terwijl van den anderen niet eene schilderij meer aan te wijzen is.

VERMEER en zijn vergeten collega drukken zich het sterkst uit: zij spreeken van vodden, niet te taxeeren omdat zij nniet geacht en konnen werden."

De dan volgende acten laten ons vermoeden, dat Fromantiou de schilderijen aan JAN WILS, zoon van den Haarlemschen schilder van dien naam, ter bewaring had gegeven, van wien UYLENBURGH te vergeefs trachtte ze terug te krijgen. Door al het heen en weer gereis schijnen de schilderijen beschadigd geworden te zijn.

$\mathrm{H}_{\mathrm{ij}}$ schijnt ze toch publiek verkocht te hebben 1) maar de reputatie van den kunsthandelaar had geleden. Daarbij kwamen de hoogst ongelukkige tijdsomstandigheden (wij hooren UyLenburgh in één der Acten klagen over "dese bekommerlycke tijcen en miserabele constitutie van het "lieve Vaderlandt") zoodat het geen wonder is, als wij kort daarna van zijn faillissement hooren ${ }^{2}$ ).

Op huyden den 21 Mey Anno 1672 compareerden ...... de Heeren JOHAN DE BAEN, Mr. Kunstschilder en Deecken, mitsgaders JOHAN LE DUCQ en JeRONIMUS vaN DiEst, insgelycxs Mrs. Konstschilders en Hooftmannen der Schilderskunst en de broedersschap van de Confrery camer deser Stede 's-Gravenhage ende hebben ten versoucke van Sr HENRICK DE FORMANTEAU (Fromantiou) voor de oprechte waerheyt getuycht, verclaert en gedeposeert waer te syn dat sy deposanten op haere Confrery Camer alhier op dato gesien en gevisiteert hebben I 2 stucks Schilderiën d' welcke op de lijste ofte cathalogus die de requirant hen deposanten heeft geëxhibeert, gestelt ende genaemt staen voor uytmuntende Italiaense schilderiën, mitsgaders getaxeert soodanigh als achter yeder stuck uytgetrocken Staet, namentlyck:

een Venus en Cupido, beelden grooter als het leven van MICHIEL Ryxdaelders Angelo Bonarotti, Hollants gelt . . . . . . . . . 350: 320

een Conterfeytsel van Giorgion del Castelfrancko van Titiaen, naer het leven geschildert ............. 250: 240

1) O. H. 1886, p. $44-46$.

8) Zie mijne "Künslerinventare", Mart Nijhoff, Igr5-19i6. 
Ryxdaelders

een harder ende harderinnetje van TITIAEN .......... . 160: I50 Weergadingh van deselve groote van TitiaEN......... I20: I 10 een dans van naeckte Kindertjens levensgroote van IACOMO PALMA 250: 240 een Venetiaense Dame van Paris Pordinon (N.B. PARIS BORdone) I60: 150 een Conterfeytsel van een Prelaet van Hans Holbeen ....... I 20: 110 een Ceres met overvloet, met veele naeckte Kindertjes van GIORGION

del Castel Franco .................. I 20 : I IO een out mans confeytsel van RaphaEl URbiN . . . . . . . . 150: 140 een St. Paulus, halfbeelt, levensgroote, van de Oude Jacomo Palma 80: 70 een Schoone Venetiaense vrouw van Titiakn ... . . . . . 200: 185 een lantschap van TitiaEN met een Satier die de nimphe Caresseert 240: 230 sijnde alle de voorsz. Schilderijen gecachetteert met het signet van syne Ceurvorstelycke Doorluchticheyt VAN BRANDENBURCH, welcke voorsz. Schilderijen niet alleen niet en sijn uytmuntende Italiaensche Stucken ofte schilderyen, maer ter contrarie niet weerdich te sijn te draegen den naem van een goet meester, veel min den naem van soodanige uytmuntende meesters daer deselve voor uytgegeven werden gedaen te syn en vervolgens dselve by haer deposanten tot een prijs van merite niet connen werden getaxeert.

Eindigende, sy hiermede.... enz.

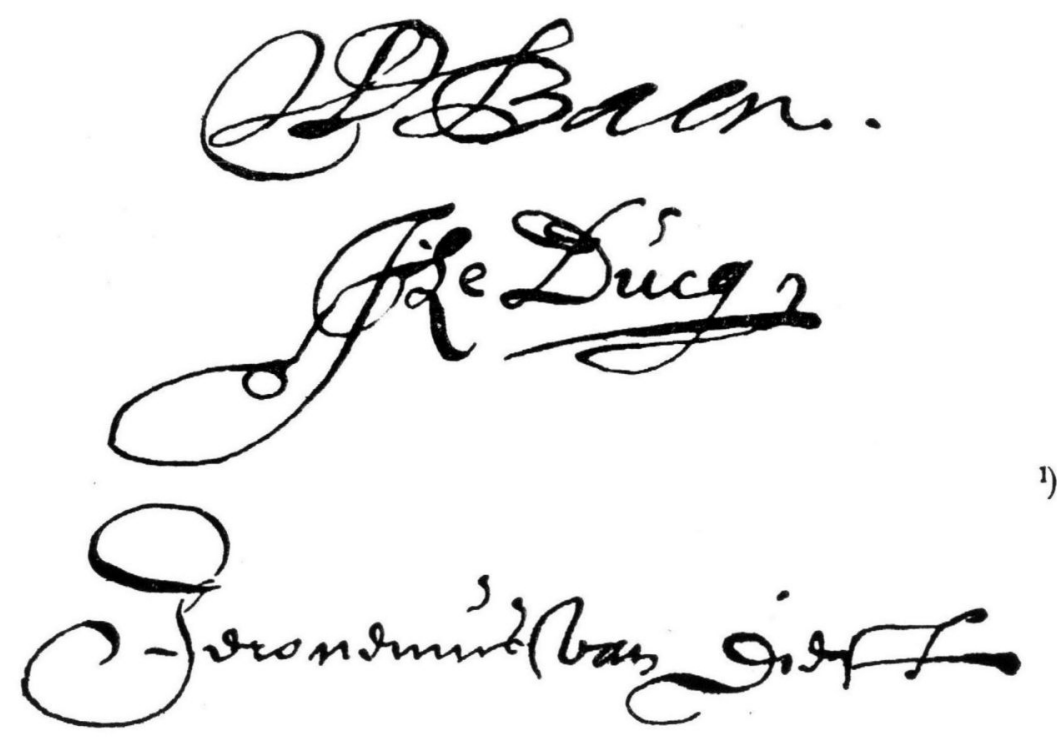

1) Prot. Not P. VAN Swieten, den Haag, 
Op huyden den 23 Mey 1672 compareerden voor mij PiEter van SwiEten, Openb: Notaris...... d' Heeren Johannes Jordaen ende Johannes Vermeer uytmuntende Kunstschilders tot Delft en verclaerden sy deposanten te saemen ter instantie van Sr. HENRICK DE FORMANTEAU enz. enz. (volgt letterlijk de inhoud van de vorige acte!)

en dan:

Sijnde de voorsz Schilderiën alle gecachetteert (enz. als voren) welcke Schilderiën niet alleen niet en syn uytmuntende Italiaense Schilderiën, maer ter contrarie eenige groote vodden ende slechte schilderiën, die op verre nae de tiende part van de voorsz. uytgetrocke prysen niet weerdich en sijn, ende sy deposanten die niet en connen estimeren, dewijle deselve niet geacht en konnen werden.

Eyndigende enz.

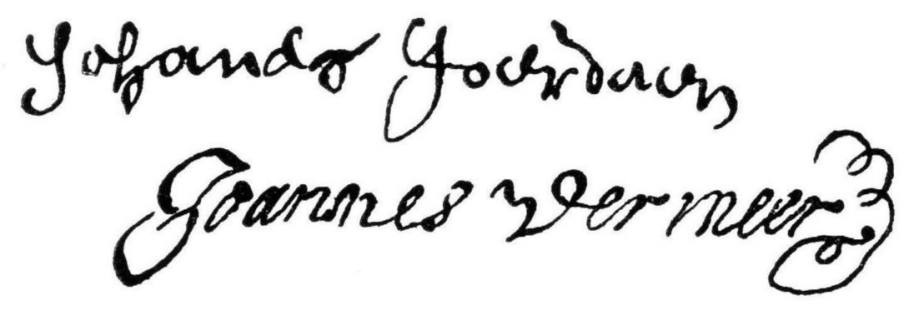

20 Juny 1672. GerardT Uijlenburgh, Mr. Schilder en negotiant in schilderijen doet HenRy DE Fromenteau tegenwoordigh binnen dese stede insinueeren:

(Over de I2 Italiaansche schilderijen in $167 \mathrm{I}$ aan den Keurvorst van Brandenburg verkocht, door Generaal Majoor Vryheer van SpaEN). I Aug. I67 I had hy een obligatie van 2771 rycxdaelders er voor ontvangen; maar die moest nog worden betaald en nu heeft de FrOMANTIOU die stukken verdacht gemaakt nalsof het maer nagemaeckte copien en gantsche slechte stucke waren, daertoe hij eenige schilders heeft gepoocht te suborneren om sulcx te verclaren".

UYLENBURGH protesteert tegen dit alles en vooral van alle costen en schaden en interessen.

De Fromantiou ,hoort en siet" en verzocht copie 1). insinuatie:

3 Januari 1673. Sr. Gerard Ulenborgh doet Sr. Jan Wils de volgende

Alsoo Henry Fromantiou tegens de waerheyt heeft gelieven voor te geven als of seeckere twaelf stucken schilderye door den insinuant voor desen

1) Prot. Not. A. LoGk, Amsterdam. 
vercocht aen de ordre van Syne Churvorstelycke Doorluchticheijt van Brandenburch en ten contentemente van syn hoochgem: Churvorst: Doorl. gelevert waeren, geen originele maer naegeschilderde copien en vodden van jongeluyden en leerlingen voor haer meesters geschildert, sulcx hem oock op de clachten van den insint is geïnsint en opgelegt sich met eenige van gen: schilderijen herwaerts nae dese stadt Amsterdam te vervoegen en met behoorlycke verclaringe van ervarene en onpartijdige meesters en kenders van de Italiaense konst te bewijsen dat deselve schilderyen geen originele maer copyen waren, twelck hy FORMENTEAU (sic) noyt in der eeuwicheyt sal connen doen, immers tot noch toe niet en heeft gedaen daeruyt claerlyck is aftemeten dat tselve niet anders en sijn als opgeraepte en gepractiseerde vuylicheden, alleen by der hant genomen om den insinuant te calumnieren injurieren en in synen goeden naem en faem te quetsen, jae waert mogelyck, hem en syne gansche negotie te ruineren sulcx daerover alrede proces van injurie tegens hem is geintameert en noch voor desen Ed: Achtb: Gerechte hangende, synde hy FORMENTEAU boven arrest en in vilipendie van de justitie van hier vertrocken, doch alvooren sijn vertreck op den $18 \mathrm{n}$ Juny verleden door de Nots. D. VAN DER GROE gelieft te laten doen seeckere frivole en ongefondeerde insinuatie daerop hem oock wegens den inst. den $20^{e_{n}}$ dito behoorlijck en fondamenteel antwoort door de Not. AdRIAEN LOCK en seeckere getuygen is toegevoecht, in plaetse van sich nae gedachte antwoort te reguleren op den $2 \mathbf{r}$ dito gelieft heeft andermaal te laeten weeten dat de gemelte schilderyen waren berustende ten huyse van u geïnsinueerde en aldaer waren voor rekeninge en risico mitsg. ten laste en pericule van den insinuant...... Ulenborgh verzoekt dus de schilderijen terug - niet om ze terug te nemen, dat kan men niet van hem vergen "te meer dewyle de waerde van alle dingen en specialijck van schilderijen en "diergelijcke rariteyten door dese bekommerlijcke tijden en miserabele constitutie "van het lieve Vaderlandt in prijs en waerde seer sijn .comen te daelen en "declineren"; hij zal de stukken terug nemen, maar de schaede en interest die "hij door de weder overneminge soude mogen comen te lyden te laeten in de "discretie van S. Churvorst: Doorluchticheyt."

WILS is nooit thuis. Eindelijk zegt zijn vrouw "dat hij de schilderyen niet "soude leveren, voor en aleer hy daertoe ordre hadde van Formenteau en dat hij daerover op Berlyn hadde geschreven". 1)

20 January I673 verzoekt UYLENBORGH nogmaals aan WILS de I2 schilderyen over te leveren en beroept zich op het appointement van schepenen van I 9 dezer. Hij begint nu te dreigen.

1) Prot. Not, A. Lock, Amsterdam. 
WILS verzoekt copie en zegt dat hij een request zal presenteeren. 1)

8 Febr. 1673. Sr. GERRIT UijlenBORCH, kunstschilder, verclaert dat hij heden in ontvangst heeft genomen de bewuste 12 schilderijen die onder Sr. JAN WILS berustten en die dezen door HENDRICK FOURMENTEAU (sic) schilder van sijn keurvorst: Deurluchticheyt van Brandenburch ter hand gesteld waren. „Doch „sijn de twee grootste stucken sonder lijsten, naementlyck de groote Venus en "Cupido van Michiel Angelo No. I en de Dansende Kinderkens van Jacob „DE Palma, de jonge No. 8, Jtem is de Troni van Hans Holbeen getekent ${ }_{\text {} N o}$. Io meer beschadicht of afgeschilvert in 't kleet dan die was ten tijde als "het selve stuck door de voorsz FoURmenteau in de verleden somer alhyer in "de herberge "de Keysers Croon" is verthoont geweest en in No. I I wesende „de Cheris (Ceres) van JoRgeon DEL CASTEL FRANCO (GIORgIONE) wat meerder „beschadicht dan het was als voren. JEAN WILS teekent mede de acte en reserveert zijne rechten. ${ }^{1}$ )

3) Prot. Not. A, Lock, Amsterdam.

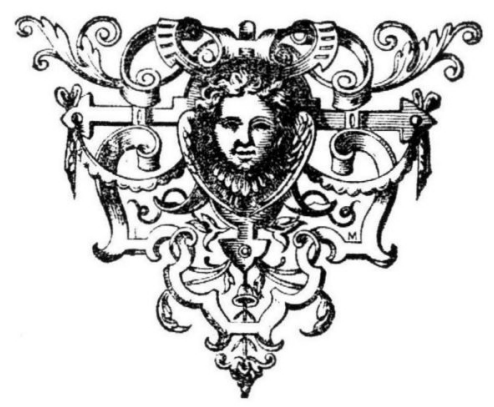

